\title{
Da retórica protetiva à pretensão punitiva: compreendendo decisões judiciais de medida socioeducativa de internação no Recife
}

\author{
Érica Babini Lapa do Amaral Machado \\ Andrielly Stephany Gutierres Silva
}

Da retórica protetiva à pretensão punitiva: compreendendo decisões judiciais de medida socioeducativa de internação no Recife

Resumo: Trata-se de pesquisa sócio-jurídica com sessenta decisões judiciais de medida socioeducativa de internação a adolescentes proferidas nos anos de 2011 e 2012 nas Varas da Infância de Pernambuco, investigando sobre a presença de códigos ideológicos do julgador na argumentação judicial. A pesquisa é quantitativa e foi utilizada como metodologia a análise de conteúdo, a fim de encontrar as relações que existem entre subjetivismos do julgador e as decisões judiciais. $\mathrm{O}$ marco teórico da pesquisa é a Criminologia Crítica, segundo a qual o desvio são qualidades (etiquetas) atribuídas a determinados sujeitos através de processos de interação social. Verificou-se que as decisões estão vinculadas a estereótipos que trazem consequências à autoimagem do jovem processado que, a contrassenso do que enuncia a Doutrina da Proteção Integral, enseja um retorno ao menorismo, tornando o adolesceste um objeto marginalizado pelos atores judiciais.

Palavras-chave: Doutrina da Proteção Integral. Sentença de medida socioeducativa de internação. Códigos ideológicos do julgador. Criminologia crítica.

From protective rhetoric to the punitiveness will: understanding judicial court decisions of juvenile incarceration in Recife

Abstract: It's a socio-judical research with sixty judicial decisions of juvenile encarcerament in the years of 2011/2012 in the Youth Courts of Pernambuco. The objective is to identify (or not) ideological codes in the decisions. The research is quantitative and was used, as a methodology, content analysis in order to find the relationships between ideological codes of the judge and the judicial reasoning. The theoretical framework is the Critical Criminology for which criminality is the result of labels assigned to specific individuals through complex processes of social interaction. The conclusion is that the trials are, somehow, linked to stereotypes, which bring consequences to social and self-image of youth, against of what the Doctrine of Integral Protection establishes. Then, it dangerously entails a return to menorism period, making the youth a manipulated object and by the actors of the process.

Keywords: Doctrine of Integral Protection. Incarceration decision youth Justice. Ideological codes of the judge. Critical criminology. 


\section{Introduzindo os marcos do Direito da Criança e do Adolescente: uma construção histórica no sentido da autonomização de sujeitos de direito}

A marcha do Direito da Criança e do Adolescente foi - e ainda o é - uma trajetória de afirmação de Direitos Humanos. Esta caminhada não se concretizou sem turbulências e muita disputa nas searas intelectuais. O processo de construção de um sistema de direitos fundamentais e, por conseguinte, um trato constitucional destes, evidencia o que em um tempo tem caráter de necessidade à existência social, e que pode, mais adiante, categorizar-se com as vestes da mais cruel injustiça universalmente condenada (MILL, 1992). No momento, imperioso se faz um sucinto relato pormenorizado de sua contextualização para melhor entendimento da complexidade que lhe é atinente.

A conceituação e tratamento jurídico da ideia de infância e adolescência não existiam antes do século XIX. Só com o avanço das ciências e com um rol de mudanças econômicas, fortalecidas na idade moderna, é que a visão de infância veio ser considerada enquanto uma etapa do desenvolvimento do ser humano, com características próprias atinentes às suas peculiaridades (RAMIDOFF, 2011).

O tratamento jurídico só começou a ser intensificado a partir do século XIX, com o advento da potencialização de critérios biopsicológicos na área do conhecimento médico acrescido ao alto grau de miséria e marginalização do quadro social europeu a partir da revolução industrial.

No Brasil, a responsabilidade penal dada à criança remete às Ordenações Filipinas, vigentes no Brasil até 1830, quando surge o Código Penal do Império. Com um Estado não-laico e com uma Igreja oficial, conceitos de Direito Canônico se confundiam com conceitos jurídicos estatais. Pela tradição católica, a idade "racional" era atingida somente aos sete anos; também do ponto de vista estatal, o marco da responsabilidade penal se dava nesta idade. Ademais, só era assegurado pelas Ordenações a inaplicabilidade da pena de morte e, em alguns casos, a redução de pena. Pelo sistema "jovem adulto", dos dezessete aos vinte e um anos, por sua vez, poderia ser até mesmo condenado à morte. Enquanto isso, na Inglaterra germinava o Direito da Infância com a Carta dos Aprendizes de 1802, à contramão da estagnação brasileira (SARAIVA, 2009).

Com o surgimento do Código Penal do Império, em 1830, após a Proclamação da Independência de 1822, a fixação da inimputabilidade penal plena se deu em 14 anos, prevendo ainda um sistema biopsicológico para punição de crianças de sete a quatorze anos. E, com a instituição da República (1889), saindo de cena o Código Penal do Império e surgindo o Código Penal dos Estados Unidos do Brasil, a imputabilidade penal vive uma pequena evolução, se estabelecendo aos nove anos a irresponsabilidade penal máxima.

Ao acompanhar tais evoluções, pode-se perceber o trato diferenciado com a causa juvenil por parte do Estado: da total indiferença à (tardia) proteção, ainda que mínima. Erigindo, sem nos esquecermos do paradigmático caso da Sociedade Protetora dos animais e da menina maltratada com nove anos, uma nova era do Direito. Antes "coisa", hoje reclamante de, minimamente, uma proteção estatal. Nascia o Direito de Menores (MENDEZ, 1998).

Paralelamente ao surgimento de variados Tribunais de Menores, influenciados pela primogenitude do Tribunal de Menores em Illinois, EUA, em 1899, construía-se a 
Doutrina do Direito do Menor. Esta doutrina teve dois marcos fundamentais para sua afirmação: a realização do Primeiro Congresso Internacional de Menores, em Paris, 1911 - o qual assentou os princípios do novo direito - e a Declaração de Gênova de Direitos da Criança, adotada adiante pela Liga das Nações em 1924, consagrando-se como o primeiro instrumento internacional a reconhecer a ideia de um Direito da Criança.

Mas, como constatou Garcia Mendez (2000), ao analisar as conclusões do Congresso de Paris, a política era a de suspensão de garantias (princípio da legalidade, i.e.) para efetivar uma "proteção" aos menores. Em nome do combate a um mal, o mal da não diferenciação entre adultos e crianças, em nome do amor à causa, surgia o caráter tutelar da justiça de menores, consagrando o aviltante binômio carência/delinquência. Afinal, o que poderia dar errado, se na cabine de controle dessa épica viagem apaixonante existia a suposta figura de um juiz investido de todas as prerrogativas do bom e velho "pater familiae"? Muita coisa deu. E assim os fundamentos da Doutrina da Situação Irregular foram lançados.

O binômio carência/delinquência, marcante da lógica operativa deste sistema, foi o fundamento das primeiras legislações brasileiras em relação ao infante Direito da Criança. Devido à resultante confusão conceitual, a nova ordem dicotomizou o universo juvenil em "crianças bem nascidas" e "crianças excluídas". A estas últimas agregando tanto as desvalidas quanto as delinquentes: surgia o termo "menor". Neste período, tivemos a Consolidação das Leis Penais, adotando um critério objetivo de inimputabilidade penal, fixando-a em 14 anos, uma migalha frente às controvertidas mudanças conceptivas.

Com o surgimento do Código Penal de 1940, seguindo a linha do direito de caráter tutelar vigente, os menores de 18 anos são declarados inteira e irrestritamente fora do direito penal, sujeitos à legislação especial, que ainda mantinha, sem distinção, os delinquentes e os abandonados.

Germina o SAM - Serviço de Atendimento aos Menores - pontapé inicial da FUNABEM, berço de todas as FEBEMs. Na chegada da década de 60, irrompe um episódio fundamental no cenário jurídico internacional, lançando o embrião de uma nova concepção acerca da infância, que, no fim da década de oitenta, acompanhando a marcha inexorável de luta pela consagração dos Direitos Humanos, irá evoluir para a elaboração da Doutrina da Proteção Integral: surge assim a Declaração dos Direitos da Criança de 1959.

Mergulhada no oceano da cultura tutelar, as diversas legislações internacionais começam a respirar a oxigenante passagem da criança como condição de objeto da norma, uma conquista do início do século XIX, para a nova condição de sujeito do processo, sujeito titular de direitos e obrigações atinentes à sua condição peculiar de pessoa em desenvolvimento. (SARAIVA, 2009)

Mas até esse advento vivia-se ainda tempos nebulosos nas legislações jurídicas relativas às crianças e aos adolescentes. Movida pela Doutrina da Situação Irregular, advém o Código de Menores, o qual elencava explicitamente seu público alvo: crianças e jovens que não se adequavam ao padrão estabelecido, que apresentavam alguma "patologia social" derivada de uma conduta social, de um problema familiar ou da própria exclusão da sociedade. Dentro do conceito de situação irregular existiriam aqueles que o Estado quisesse que existissem dado à sua proposital amplitude. Com o 
advento da FEBEM, consagra-se o sistema de controle da pobreza, uma vez que se aplicam sanções de privação de liberdade a situações não tipificadas como delito, ao arrepio de garantias processuais.

Paralelo ao surgimento da expressão máxima da Situação Irregular, o Código de Menores brasileiro, a ONU estabelecia o ano de 1979 como o Ano Internacional da Criança. Na Convenção das Nações Unidas de Direito da Criança de 1989, no trigésimo aniversário da Declaração dos Direitos da Criança, a Assembleia-Geral da Organização das Nações Unidas aprova a Convenção sobre os Direitos da Criança, elevando o status do Direito da Infância e Juventude ao nível de um documento global com força coercitiva.

O paradigma se inverte. Criança e Adolescente agora na condição de sujeitos de direito, protagonistas de sua própria história, com direitos e obrigações peculiares à sua formação; Justiça de Infância e Juventude ganha novo contorno; abandono do conceito de menor: uma nova era para o mundo fático e jurídico da criança e adolescente se iniciava. Na companhia da evolução internacional, a Constituição Federal de 1988 antecipou-se à Convenção, adotando a Doutrina da Proteção Integral antes mesmo de sua histórica consagração pelo texto da ONU, proclamando-a em seus Art. 227 e 228.

Todo o arquétipo de garantias galgado pelo Direito Penal como bandeira de um Estado Democrático de Direito estende-se à criança e ao adolescente. Princípios fundamentais, antes relativizados em nome de uma suposta ação protetiva do Estado, passam a fazer jus ao seu nome e se tornam indispensáveis à rotina de processo envolvendo crianças e adolescentes em situação conflituosa com a lei.

Edifica-se a privação da liberdade como exceção e apenas mediante ordem expressa de uma autoridade judiciária ou em flagrante. Desintegra-se o ícone maior da Doutrina finda, o Juiz de Menores, investindo-o apenas de funções estritamente jurisdicionais, reservando-o ao seu papel de julgador. Sai de cena o juiz ilimitadamente empoderado; surge o Juiz Técnico, com atuação expressamente demarcada.

A consagração da Doutrina da Proteção Integral tornou-se um marco direcionador das conseguintes políticas públicas relativas à criança e ao adolescente. Não por acaso nasce, em 1990, com a edição da Lei n. 8069/90, o Estatuto da Criança e do Adolescente (ECA). Considerado como a versão brasileira da Convenção das Nações Unidas dos Direitos da Criança, o ECA marcou a história evolutiva dos direitos atinentes à infância e juventude: foi, definitivamente, um marco, uma verdadeira catarse.

Ainda, impossível olvidar que, para fazer valer seu sistema de garantias (FERRAJOLI, 1999), o ECA estruturou-se em um sistema tríplice, harmônico e preventivo: um primário, voltado às políticas públicas de atendimento (para toda a população infanto-juvenil); o secundário, que remete às medidas de proteção voltadas aos jovens em situação de risco pessoal ou social; e o terciário, que se preocupa com as medidas socioeducativas, direcionada àqueles que praticaram conduta infracional. $\mathrm{O}$ conceito de ato infracional, no ECA, confere à responsabilização o caráter de medida socioeducativa, por clara intenção de fomentar uma perspectiva pedagógica à medida.

A despeito dessa paradigmática virada - que passa a ver e tratar crianças e adolescentes como sujeitos de direitos, refutando a antiga ideia de objetos da tutela estatal - problematiza-se se a mudança foi totalmente assimilada pelo imaginário social e pelos representantes do Poder Judiciário e seus agentes. Verificou-se através desta 
pesquisa que, malgrado as reais tentativas de mutação de concepções sociais a partir da reformulação de ideais jurídicos, a implementação da nova política inspirada no novo paradigma ainda acontece guardando indesejados resquícios do antigo sistema de caráter menorista.

Pode-se observar que o público que constitui a população jovem em conflito com a lei é, quase majoritariamente, provinda de classes marginalizadas, cujos atos infracionais guardam estrita relação com problemas de acesso à renda, sem descuidar do ostensivo aumento de internação de adolescentes de 2007 a 2011 (CNJ, 2011).

Como alude Salo de Carvalho (2010), as taxas de encarceramento são construções políticas que decorrem de decisões em esferas distintas, sejam elas decisões legislativas, sensibilidade judicial e/ou capacidade e limites do próprio sistema para processar os diversos atos delitivos.

O aumento de pessoas reclusas, e aqui resguarda-se os adolescentes, não reproduz inexoravelmente o aumento da delinquência, não obstante seja esse o engodo midiático nos empurrado goela abaixo (ZAFFARONI, 2007). E a mídia possui um papel protagonista dentro do cenário político-criminal: ela define a pauta do cotidiano e expõe os personagens que a encarnam. Funciona como uma espécie de espelho do ambiente social. Contudo, um espelho altamente seletivo. Seletividade do surpreendente ou do conveniente.

Tal qual ROSA (2003) sustenta: “[...] qualquer mídia, em qualquer lugar do mundo, embute em seu âmago um certo grau de distorção, pois não reflete a realidade como um todo, senão seus aspectos capitais". A proposta midiática clama por mecanismos de promoção de medidas emergenciais, elevando a função simbólica do sistema penal eminentemente repressivo. Unida à desconfiança acerca de uma paulatina mudança na atuação dos agentes judiciários, os quais dão a real efetividade à sede punitiva deflagrada na órbita legislativa, se tem procurado problematizar o nível do real cumprimento das garantias legais na imputação de medidas socioeducativas de internação por parte dos magistrados no momento da sentença. Para assim buscar perquirir o grau de influência de subjetivismos na construção argumentativa, sob um véu dissimulador e vilmente retórico acerca da natureza pedagógica da medida, ocultando, em verdade, uma pretensão de punir.

\section{Marco teórico de orientação: Criminologia Crítica em ação}

A Criminologia Crítica foi o marco teórico que se imbricou a presente pesquisa, buscando desenvolver uma análise crítica acerca da realidade jurídico-penal e também de suas políticas sustentadas pelo Estado, a fim de identificar suas reverberações no tocante ao Estatuto da Criança e do Adolescente e a toda a política sócio penal voltada ao universo infanto-juvenil.

O viés crítico da lupa criminológica, arguido mais fortemente na década de 60 , após uma virada paradigmática em suas inspirações de análise, leva a um breve passeio por sua evolução.

A criminologia comporta uma série de definições desde suas origens europeias, quando foi articulada e pensada pela primeira vez até a recepção hegemônica por um país periférico desde sua origem (DEL OLMO, 2004), como o Brasil. 
É indiscutível que aqui não seria o espaço mais apropriado para discutir o curso de rupturas e permanências dos discursos deste saber ${ }^{1}$, por evidente incongruência com os objetivos do texto. Porém, é importante compreender a origem do discurso criminológico. Não se olvida aqui os arriscados saltos que serão realizados (OLIVEIRA, 2004), porém, por não se pretender realizar a história social das ideias, talvez se justifique.

Costumeiramente, identifica-se a origem da Criminologia no século XIX com a sua oficialização como saber. No entanto, ZAFFARONI; BATISTA (2003) apontam a Inquisição, o martelo das bruxas, o primeiro livro de criminologia da história, em que os demonólogos são os primeiros teóricos e exorcistas, os primeiros clínicos.

$\mathrm{Na}$ construção de sua hipótese vale-se de Foucault (2009) que indica os discursos como práticas sociais destinadas à definição de subjetividade, posto não ser o sujeito um ser a priori, mas resultado das forças e das formas políticas, econômicas etc.; as quais delinearão a construção do sistema penal.

Neste sentido, a história dos programas criminalizantes irá girar em torno da posição da vítima - desde a limitação da vingança privada até a supressão a sua debilidade, sujeitando-a a signo que habilita o poder confiscado pelo novo Estado que fala por ela e é lesado por quando ela, a vítima, é lesada.

As mudanças das futuras formas jurídicas conhecidas como Estado, soberania, burocracia, delito e castigo partem com o destaque sobre o método de aquisição da verdade e a forma de solução de conflito que saiu do duelo, expressado pelo complexo de Édipo na Grécia para ser confiscado por um novo ente, o soberano. Assim surge a ideia de infração como uma lesão ao Estado, à lei, cuja reparação deve ser concretizada (FOUCAULT, 2009).

Com o redescobrimento do direito romano e as posteriores glosas dá-se uma mudança das regras processuais do acusatório para o inquisitório, e assim alguns elementos são incorporados à busca pela verdade: o caráter público, o sigilo sobre o delator, a configuração numa só figura de julgador, defesa e acusação, provas tarifadas, sendo a confissão a principal dela, autorizando, portanto a tortura autorizada como ferramenta essencial (CARVALHO, 2104).

Desse modo, o corpo econômico-político coerente na Europa fora corporificado pela igreja nos séculos X, XI e XII, representando ao mesmo tempo o inquérito espiritual dos pecados e das faltas e os inquéritos administrativos. Não por acaso, mas como resultados das forças políticas uma forma de o poder se exercer (FOUCAULT, 2009).

Quer-se dizer, a Inquisição de 1215 no quarto Concílio de Latrão, com a finalidade concreta de perseguir a heresia dos cártaros do Languedoc é tido como a raiz do poder punitivo, sendo o discurso do Malleus o primeiro de ordem criminológica moderna. Ao explicar as causas do mal e os métodos de combate-lo, é o mesmo da criminologia etiológica do século XIX (ZAFFARONI, BATISTA, 2003).

Do ponto de vista criminológico a Escola Clássica ${ }^{2}$ que em si não pode ser considerada uma escola, por não compartilhar padrões de pensamentos equivalentes,

\footnotetext{
${ }^{1}$ Um dos caminhos para se conhecer os discursos criminológicos está em ANITUA (2008). Também tratando da mesma temática em (PAVARINI, 1983)

${ }^{2}$ Sobre o Iluminismo penal esclarece Zaffaroni “(...) jamás pueden ser colocadas bajo el rótulo de una 'escuela', porque la 'escuela clásica' nunca existió, sino que la inventó Enrico Ferri, como denominación
} 
desempenha papel específico o curso dos discursos dos saberes criminais. Contudo, não se tratando este texto de uma historiografia, valendo-se dela somente para compreender a linha teórica que orienta este trabalho, não irá aqui se debruçar, dando-se um salto (proposital) para o século XIX, período no qual se identifica profunda interrelação entre os discursos demonológicos já discutidos e a Escola Positivista que consolida a criminologia.

Evoluindo para a Escola Positiva, conforme nos ensina Vera Andrade (1997), a Antropologia Criminal de Lombroso e a Sociologia Criminal de Ferri foram duas matrizes fundamentais na conformação do chamado "paradigma etiológico" da Criminologia, que se associou à tentativa de auferir à disciplina o estatuto de ciência, dentro dos pressupostos epistemológicos do positivismo, em adequação ao fenômeno de cientifização do controle social do fim do século XIX.

A criminalidade, segundo tal entendimento, é concebida como um fenômeno natural. Outrossim, no paradigma etiológico, a Criminologia deve explicar as causas do crime, segundo o método científico ou experimental e o auxílio das estatísticas criminais oficiais, sendo capaz de prever os remédios para combatê-la. A Criminologia, assim, tem papel de defesa da sociedade.

Entretanto, a máscara da tão defendida bandeira da cientifização erguida pelos criminólogos positivistas começa a cair ao surgirem questionamentos sobre seu grau de adequação aos postulados científicos. Aniyar de Castro (2005) derriba a Escola Positiva

Por trás dela está também o modelo do consenso, embora o positivismo recuse expressamente qualquer enquadramento sóciopolítico. Sua insistência numa suposta neutralidade não pode enganar, porque, apesar de, como filosofia, centralizar toda a autoridade e todo o poder na ciência, o positivismo como criminologia não questionou a ordem dada, e saiu, código na mão, a perseguir o que desde então passou a se chamar de delinquentes natos, loucos morais, personalidades criminosas, desagregados sociais, inadaptados, etc. (as definições são tão variadas quanto as próprias variantes do positivismo criminológico), fazendo assim tão pouca ciência quanto a que criticava nos criminólogos anteriores a essa escola. Considerando anormais ou desviados os assinalados por uma decisão política (a Lei), contradizia os postulados de sua pretensão científica.

Assim advém uma mudança paradigmática: entra em cena o paradigma da reação social, escudado em meados do século passado e consagrado no surgimento do labeling approach.

común para todo lo que fue anterior al positivismo. En varias ocasiones hemos demonstrado que no puede ser una 'escuela' el conjunto de opiniones de los pensadores del tema político-criminal durante más de un siglo, vertidas desde las ideologías más dispares (kantismo, hegelianismo, idealismo romántico, utilitarismo, vueltas parciales al aristotelismo, pensamiento iluminista, etc.). Además, la circunstancia de que estos autores, justamente, hayan sido quienes al plantear la cuestión político-criminal dieran origen a la presentación actual de la criminología, nos exime de cualquier comentario acerca de su tradicional asignación al terreno del derecho penal. Más aún: consideramos que su ubicación en el ámbito exclusivo del derecho penal con un rótulo unitario - y su consiguiente exclusión del ámbito criminológico - es un modo de minimizar su importancia y de prevenir- se contra el efecto deslegitimador que puede tener el discurso contractualista. (ZAFFARONI, 2003, p. 128). 
De inspiração marcadamente fenomenológica, com a junção do interacionismo simbólico $^{3}$ à etnometodologia ${ }^{4}$, o labeling approach define sua tese principal na ideia de que o desvio e a criminalidade não são qualidades intrínsecas da conduta; não têm caráter ontológico pré-constituído à reação social, mas são, na verdade, qualidades (etiquetas) atribuídas a determinados sujeitos através de complexos processos de interação social.

Contrariamente à sua anterior escola, a criminologia vem afirmar: não há conduta criminal em si, tampouco há concretos traços de personalidade que possam configurar "O criminoso". Surgem os termos "criminalização" em contraponto a "criminalidade" e "criminalizado" a "criminoso".

Neste momento, relevante é a contribuição de Becker (2008). Com seus estudos sobre o desvio, a partir do qual observa que um ato é ou não desviante a depender de como as outras pessoas reagem a ele, estabelece dois pontos fundamentais no paradigma da reação social: a conduta desviada e a reação social.

A partir do momento que se solidifica a ideia de que os grupos sociais criam o desvio ao produzirem regras cuja infração constitui o próprio desvio, aplicando as regras a certas pessoas em particular e as qualificando como marginais ou estranhas, a criminologia erige-se a outra estágio.

Ademais, a depender de quem comete o ato desviante ou de quem se sente prejudicado por ele, podemos averiguar o grau de desvio desse mesmo ato, pois as regras tendem a ser aplicadas a algumas pessoas em detrimento de outras. Becker (2008) constatou por um estudo da "delinquência" juvenil que jovens de classe média têm o tempo de duração do processo encurtado quando relacionados com processos de jovens de classe subalternas, inclusive com mínimas chances de condenação, ainda que ambos se enquadrem na mesma infração. E aqui Becker alude à questão do poder, de modo que determinados grupos em posição social que lhes fornece armas e poder têm mais capacidade de imposição de regras a outros grupos.

Contudo, é justamente nesse ponto que os teóricos do labeling approach encontram suas limitações. Do movimento nomeado de "A nova Criminologia", cuja obra homônima de Taylor-Walton-Young de 1973 marca o trânsito da recepção das teorias norte-americanas anteriormente expostas à elaboração de uma criminologia marxista, sobrevém a radicalização da perspectiva do etiquetamento, que se iniciou com as teorias do desvio, através de uma imersão no materialismo histórico na realização do estudo do desvio e da alocação do desvio num contexto mais amplo de luta de classes (LARRAURI, 2000).

$\mathrm{O}$ embrião do que mais a frente vem a ser a Criminologia Crítica nasce de concordâncias e insurgências referentes à teoria do etiquetamento. Alegavam os "novos criminólogos" que os teóricos do labeling approach concentraram-se demasiado no processo de criminalização em si, esquecendo-se de realizar questionamentos no tocante às condicionantes estruturais e à influência do viés econômico dentro de um poderoso enfoque político.

\footnotetext{
${ }^{3}$ Concepção teórica em que o significado é o conceito central e os objetos sociais são construídos e reconstruídos pelos atores envolvidos de forma interminável, ou seja, o significado social dos objetos se deve ao fato de lhes dar sentido no decurso de nossas interações.

${ }^{4}$ Considera a realidade socialmente construída presente na vivência cotidiana de cada um e que em todos os momentos podemos compreender as construções sociais que permeiam nosso entorno.
} 
Pensou-se no desenvolvimento de uma criminologia que colocasse a questão criminal e a reação social em uma perspectiva histórico-analítica. Com essa guinada, a Criminologia Crítica recupera, desse modo, a análise das condições objetivas, estruturais e funcionais que são acusadas de originar, principalmente na sociedade capitalista, o fenômeno do desvio, enxergando-os de modo díspar na medida em que provém de classes subalternas ou de classes dominantes (ANDRADE, 1997).

Além disso, verifica-se o deslocamento dos estudos das causas do desvio criminal para os mecanismos sociais e institucionais pelos quais é construída a realidade social do desvio e, também, para os mecanismos criadores das definições do desvio e da criminalidade (BARATTA, 1999).

Propondo-se a vincular teoria à prática e a analisar mais a fundo a função que cumpre o Estado, as leis e as instituições legais na manutenção de um sistema de produção capitalista, dentre outras propostas, a Criminologia Crítica transcende os limites das teorias da rotulação (de contribuição inegável), rompe com uma criminologia de caráter tipicamente liberal e alça voo em busca de elaborar uma teoria do desvio realmente social. O que antes foi apenas contemplado pelos teóricos do labeling, por meio dos novos criminólogos, seria dissecado a fim de realizar uma verdadeira transformação social, como preconizava Marx em seus escritos (LARRAURI, 2000).

Nesse âmbito, a presente pesquisa se propôs, a partir do método da análise de conteúdo compreender a natureza da medida socioeducativa de internação sob o olhar do magistrado para verificar a existência ou não da pretensão de punir escamoteada pelo discurso da socioeducação, possivelmente presente nas sentenças aludidas.

A hipótese é a de que - por descrer-se do juiz neutro e infalível, eivado, na verdade, de todo um modus operandi na tradição jurídica, mergulhado dentro de um contexto social punitivista, em que o crime é um subproduto final do processo de criação e aplicação das leis, orientadas ideologicamente às classes dominantes (BARATTA, 1999), compreendendo a realidade criminal enquanto um desvio etiquetável e não ontológico - os julgamentos estão, de certo modo, vinculados a estereótipos, que, malogradamente, trazem consequências acintosas à imagem social e autoimagem do jovem infrator.

Entende-se, ainda, que os julgamentos solapam uma tendência punitiva da práxis jurídica à aparência pedagógica da medida aplicada ao adolescente, que, a contrassenso do que enuncia a Doutrina da Proteção Integral, assegurada constitucionalmente, perigosamente pode retornar a ser um objeto manipulado e marginalizado pelos atores do processo, sugerindo um não desejado retorno à pretérita Doutrina da Situação Irregular.

Realizou-se a pesquisa por meio do método dedutivo de revisão bibliográfica, a fim de aferir a consolidação teórica das hipóteses, para a qual foram utilizadas não só bibliografias que ajudaram a solidificar o conhecimento jurídico e político acerca do Estatuto da Criança e do Adolescente, como também bibliografias que proporcionaram uma maior compreensão do sistema de justiça criminal lato sensu e um maior aprofundamento na temática do desvio.

Ainda, foi realizada uma análise mais crítica do sistema punitivo do jovem em conflito com a lei, com o propósito de diagnosticar como atuam os magistrados das Varas de Infância e Juventude, com intenção de compreender menos nebulosamente as 
influências de pressões sociais, formadoras do imaginário social do magistrado, com as devidas demarcações acerca da manipulação midiática, cultura do medo e outros fatores configuradores da sociedade punitiva.

A pesquisa tem por objeto de análise de sentença de imputação de medida socioeducativa de internação ano de 2011 e $2012^{5}$ proferidas nas Varas da infância e da Juventude da cidade de Recife.

O método de análise proposto é a análise de conteúdo (BARDIN, 1977), um conjunto de técnicas de pesquisa cujo objetivo é a busca do sentido ou dos sentidos de um documento, como técnica para análise dos dados. A análise de conteúdo é um conjunto de técnicas de análise das comunicações, que utiliza procedimentos sistemáticos e objetivos de descrição do conteúdo das mensagens, com um rigor de objetividade e uma hermenêutica controlada, a fim de instigar o investigador a buscar o oculto em qualquer mensagem, baseados na dedução, com finalidade na produção de inferências.

Produzir inferências, em análise de conteúdo, significa, não somente produzir suposições acerca de determinada mensagem, mas embasá-las com pressupostos teóricos de diversas concepções de mundo e com as situações concretas de seus produtores ou receptores - situação concreta que é visualizada segundo o contexto histórico e social de sua produção e recepção (BARDIN, 1977). Assim, foi possível encontrar inconscientes coletivos por trás de aparentes incoerências ou compreender estereótipos de papéis, como imaginado na hipótese principal desta pesquisa.

Para o levantamento da coleta de dados, novamente foi utilizada a máscara de dados no Software SPSS (Statistical Package for Social Sciences), programa computacional de quantificação de dados, cujo conteúdo consiste em 21 categorias de análise, que busca identificar a presença de códigos ideológicos (extra-legais) nas decisões judiciais, mormente no que diz respeito aos problemas conceituais ontológicos e teleológicos da medida.

Para que houvesse uma correta análise dos dados da pesquisa em estudo elaborouse um sistema de categorização e sub-categorização (CAMPOS, 2004) para realizar uma operação de classificação de elementos constitutivos de um conjunto por diferenciação e, seguidamente, por reagrupamento segundo o gênero. Neste sentido, foi elaborada a categoria: metaregras do julgador.

Por último, mas não menos importante, ressaltamos a importância da menção à técnica da bricolagem de significantes (ROSA, 2004), tendo como base a análise dos significantes ao longo do processo e no momento da decisão judicial.

Alega Alexandre Morais da Rosa que o juiz, seguindo tal técnica, não se vincula à acusação, mas constrói sua decisão por fragmentos, de acordo com os significantes até chegar ao ato decisório. A partir das pretensões de validade enunciada pelas partes, já no ato decisório, o juiz esquematiza, monta a verdade processual, utilizando-se para isso não só da lógica, mas também do conjunto de significantes. Da análise da construção de decisões jurídicas, é preciso que se perceba a influência dos efeitos da política, das ideologias, dos pré-conceitos pessoais (in)conscientes, ou seja, de como atuam os determinantes conotativos presentes no senso comum teórico e na singularidade do

\footnotetext{
${ }^{5}$ Não foi possível assegurar o quantitativo do universo de sentenças de internação proferidas nestes anos, tornando inviável o cálculo de uma amostragem; posto que o Poder judiciário não retém o controle anual de decisões desta natura. Logo o número de 60 sentenças é exploratório, somente.
} 
julgador, uma vez que, desse conjunto, surge a decisão.

É importante desde logo alertar que houve dificuldade de acesso ao objeto, posto que a Vara da Infância não detém o controle de identificação processual de que autos de processo houve imputação de internação provisória. Deste modo, a definição do universo para a extração de uma amostragem restou inviabilizada.

\section{Meta-regas e subjetivismos: o discurso punitivo encoberto pelo protetivo: um retorno ao menorismo}

Tendo já apreciado a evolução da Criminologia Crítica, perpassando toda a contribuição do labeling approach, válido se faz aludirmos à representatividade da teoria arquitetada por Edwin M. Schur, em seu livro Labeling Deviant Behavior (1971).

Através de seus escritos, obtém-se outra tônica relativa à questão da estereotipação. Schur preconiza que muitas pessoas desfrutam de certo conforto na crença de que atos violentos são cometidos de forma predominante por aqueles "indivíduos doentes" e talvez também na crença de que os "doentes mentais" estão sempre inclinados a cometer atos violentos.

Transladando tais aferições até a categoria geral de desvio, observar que essa preferência pela consistência de estereótipos serve não só para moldar nossa atitudes gerais no tocante ao desvio, como também para afetar indivíduos que já enfrentam graves imputações com sua identidade desviante, prevaricando sua autoimagem (SCHUR, 1971).

Schur constatou ainda que, nos níveis de interação pessoal, as consequências do estereótipo do desvio, quando aparente, podem não apenas influenciar as expectativas dos outros, mas também causar sérios problemas de resposta e gerenciamento de identidade dos desviados.

Similarmente, práticas organizacionais, em particular a de seleção e processamento de indivíduos pelas agências de controle, muitas vezes refletem estereótipos públicos comuns ou ideologias organizacionais mais específicas fundamentadas no pensamento estereotipado.

Outro ponto central do estereótipo é sua vocação a ser considerado o "status máximo". Estereotipar envolve uma tendência de pular de uma única pista ou um número pequeno de pistas, de suspeitos ou de comportamentos alegados para a mais geral figura do "tipo de pessoa" com a qual se está lidando.

Tal tendência envolve outro aspecto importante da rotulagem: a interpretação retrospectiva. Essa faceta do processo de etiquetamento envolve o mecanismo pelo qual os reatores vêm a se transformar nos tais desviados ou nos suspeitos de desvio. Tal aspecto será mais detalhado na medida em que formos o confrontando com nossos dados obtidos na vigente pesquisa.

Antes, necessário se mencionar o fato de que o Estatuto da Criança e do Adolescente carece ser aperfeiçoado. E aqui o que se pondera é sobre o espaço de discricionariedade, concedido pela legislação internacional, dada a diversidade de necessidades dos adolescentes.

Esta abertura, porém, como se verá tem levado ao avanço do arbítrio na execução das medidas socioeducativas, quase como um corolário lógico desta lacuna legislativa (COSTA, 2005). 
Alimenta-se, portanto, a hipótese da possibilidade de existência de códigos ideológicos que influenciam o magistrado no momento de sua decisão. Tais códigos podem ser resumidos em torno dos subjetivismos, preconceitos, estereótipos, que de forma conjunta, constroem a interpretação retrospectiva dos fatos por parte dos atores jurídicos, camuflando uma tendência punitiva com ares educacionais.

Estes, os atores jurídicos, parecem ser incapazes de conceber um caminho próprio. Dispostos a permanecer no enclausuramento da segurança lógica, dotada de pré-conceitos, pré-noções, ficções e estereótipos, tudo em amor à justiça e à segurança jurídica, se negam a realizar o necessário conflito de sentido do antagonismo de posições, que viria a tornar profícuo o processo hermenêutico (ROSA, 2004).

Nesse âmbito, a interpretação retrospectiva se dá de tal forma: os atores jurídicos realizam um processo através do qual reinterpretam o passado comportamental à luz da nova informação concernente ao desvio. Estes reveem o passado de interações do indivíduo em questão, procurando por sutis pistas e nuances de comportamento que podem dar mais uma prova do alegado desvio (SCHUR, 1971).

Os magistrados se utilizam de elementos referentes à personalidade do adolescente, aos grupos em que convive, ao seu estado emocional e psíquico, à sua vivência escolar, comunitária e familiar com o "simples" propósito de fundamentar não só a aplicação da decisão como também a escolha do tipo de medida e seu grau de gravidade, mesmo quando não há indicativos de autoria e materialidade.

São as pistas e nuances antes referidos; são os indícios necessários - assim significados ao bel prazer do agente significador; são as falaciosas ideias de que o juiz, paladino dos fracos e oprimidos, pode suplantar eventuais deficiências na socialização, através do peso de sua caneta.

Ora, sabido que a medida, embora teleologicamente socioeducativa, possui caráter de responsabilização diferenciada, sem, por posição político-jurídica, abarcar as penosas contradições que o reconhecimento de uma natureza penal poderia trazer, o adolescente em conflito com a lei será responsabilizado pela suposta infração que cometeu ou por, em razão do acaso da vida ou do destino de uma onisciência superior, ter nascido no lugar em que nasceu, por ter a família que têm, por ser quem ele é, numa infeliz tentativa de reenquadramento de personalidade e normatização de corpos, vislumbrando-se um (i)legítimo Direito Penal do Autor? Sobre tal tema, discorre Raúl Zaffaroni (2002)

Seja qual for a perspectiva a partir da qual se queira fundamentar o direito penal do autor (culpabilidade de autor ou periculosidade), o certo é que um direito que reconheça, mas que também respeite a autonomia moral da pessoa, jamais pode penalizar o 'ser' de uma pessoa, mas somente o seu agir, já que o direito é uma ordem reguladora de conduta humana. Não se pode penalizar um homem por ser como escolheu ser, sem que isso violente a sua esfera de autodeterminação.

Prosseguindo, na categoria de metaregras do julgador, encontramos tal procedimento retrospectivo, numa verdadeira confusão procedimental e metodológica: a medida, esquizofrenicamente, fundamenta-se em sua finalidade. Ou seja, confunde-se motivação com finalidade, ser com dever-ser, fato e direito com axiologia 
(FERRAJOLI, 2002). Mas não se confunde a práxis. Essa permanece intocável. Assim, paradoxalmente, segregação e socioeducação caminham juntas na esteira da prática pedagógica enclausuradora, que promete emancipar, mas que, antiteticamente, marginaliza.

Vejamos as análises. Das 60 sentenças analisadas, 33 das 45 que continham relatório do CENIP, totalizando um percentual de 73,3\%, explicitam que existe a necessidade de aplicação da medida socioeducativa de internação para que $o$ adolescente compreenda o mal que fez.

Aliando isso ao fato de que 68,3\% das 60 sentenças analisadas imputaram ao adolescente exclusivamente a internação, obliterando-se de sobremodo a aplicação conjunta a outras medidas protetivas. Observa-se uma tendência dos magistrados à ligação da medida de internação a uma ideia de retribuição, pois, o que é, para o magistrado, "compreender o mal que fez" senão um castigo? E se é mesmo castigo, é penal. Sendo penal, mas com véu de pedagogia, os vilipêndios às garantias penais e processuais (em razão da confusão legislativa do ECA, que apresenta orientações acusatórias com nítidos elementos inquisitórios) tornam-se ainda mais ultrajantes (COSTA, 2005).

Quando observamos que em $71,7 \%$ dos casos o juiz valora a situação familiar do adolescente para fundamentar sua decisão de aplicação da medida, podemos perceber que o adolescente é culpabilizado por motivos de que não fez escolha: não se escolhe sua família.

Uma eventual deficiência familiar não pode servir de justificativa de internação, como foi utilizada em 18,6\% dos casos em que se valora, apostando-se que a medida terá a capacidade de reaproximar pais e filhos - o que parece ironia, não?

Corroborando a hipótese da presente pesquisa, em 93,3\% dos casos em que o item dependência de drogas é valorado. O magistrado acredita que o adolescente é incapaz de ressocialização, devendo a medida de internação suprir essa incapacidade. E nos 6,7\% restantes, o magistrado valora positivamente o adolescente não ser um usuário de drogas. Trocando em miúdos: se o uso de drogas foi valorado, ele foi valorado negativamente. Isto incita a pensar: o que leva o juiz a pensar no aprisionamento de uma liberdade em virtude do consumo de substâncias entorpecentes? Não seria isso um reavivamento do discurso etiológico, através desse Estado Intervencionista, na missão triunfante de defender os cidadãos "bons e sadios" dos "maus e doentes" - discurso esse incrivelmente curial à mídia e à classe dominante? (ROSA, 2004).

Ademais, em 33 das 60 decisões, o juiz valora as influências negativas do meio no concernente ao risco pessoal e social do adolescente. Das decisões em que se valora tal item, $97 \%$ acreditam que, por estar o adolescente vulnerável às influências negativas do meio, deve-se aplicar a medida de internação. O que são influências negativas? Existe objetividade no conceito? O juiz é régua moral, soberano ser ético? Sobre tal tema, COUTINHO (1982):

É, em suma, de se fazer prevalecer a ordem sobre a desordem; porque os desordeiros estão contra os ordeiros. As pessoas desordeiras incluem "pessoas não respeitáveis, turbulentas ou imprevisíveis: catadores de papel, bêbados, viciados, adolescentes arruaceiros, prostitutas, vadios e os perturbados mentais'. [...] São acredite-se, se for possível - os 'bêbados fedorentos' e os 'pedintes inoportunos'. [...] Nós contra eles, num verdadeiro labelling approach (etiquetamento) 
antecipado: os desordeiros de dentro precisam ser controlados; os de fora, excluídos. [...] são os 'forasteiros' ou 'estranhos' que cometem crimes. [...] Os 'regulares', por sua vez, tendem a não causar problemas. Controlando os desordeiros, prendendo-os, excluindo-os, o problema estará resolvido. A ordem voltará a reinar e o crime desaparecerá.

Aos moldes do auferido por Schur e todo o arcabouço da Criminologia Crítica, o que é isso senão uma declarada construção da criminalidade, ao pescar no passado do jovem informações sem correspondência ontológica com o suposto ato infracional?

O que passa a existir é, na verdade, uma correção não por critérios objetivos, baseados tão somente na conduta transgressora de bens jurídicos por parte do adolescente, mas pelo imaginário do magistrado, mascarada pelas ilusões de segurança e dissimulada por devaneios pedagógicos (ANDRADE, 1997).

Tanto que, esquizofrenicamente, 98,3\% das sentenças declaram ter a medida caráter penal em contrapartida a $86,7 \%$, do mesmo universo de sentenças, que afirmam ter caráter pedagógico. Enquanto, em $90 \%$ das sentenças, os magistrados entendem que há uma necessidade mais enérgica da medida para que surta efeito pedagógico, vislumbrando-se talvez uma prevenção especial com a medida, 55,6\% das sentenças que valoram o item da defesa social e $75 \%$ das sentenças que valoram o item da exemplificação aos demais adolescentes acreditam que há função de prevenção geral da medida, ao afirmar que não só há necessidade de aplicação da medida com o fim de conter a violência, mas também com o fim de, através da punição, servir de exemplificação para os adolescentes outros.

Um equívoco, pois, por dois motivos: i) não existe certeza sobre o nexo causal entre o comportamento criminalizável e a pena, o que pode levar à reflexão de que a pena mais estabiliza e reproduz o universo criminal do que o extingue, como aprioristicamente se pretendia; ii) o princípio da condição peculiar de desenvolvimento impede que o adolescente seja tratado como meio de atingir fins sociais com o propósito de definição de mínimos éticos necessários, tal como se presta a prevenção geral, para a convivência coletiva (OTERO, 2007). Mais um fator que enriquece a discussão acerca da dicotomia pedagogia/pena.

A situação agrava-se quando, em 55 sentenças das 60 sentenças analisadas, o magistrado realiza interpretação extensiva por acreditar que a medida socioeducativa não possui caráter penal. Ora, para considerar garantias, não preciso figurar numa realidade penal, posto que aquelas não decorrem desta, mas sim consubstanciam-se enquanto direitos subjetivos de materialidade fundamental, próprias e configuradoras do Estado Democrático de Direito.

Observamos, assim, que o magistrado, ao julgar utilizando-se de códigos sociais extralegais, sem realizar a devida (re)leitura, tendendo a apenas repetir o que já tem de mentalmente sedimentado (seus pré-juízos), impedindo de existir a dialética entre o familiar e o estranho para brotamento daquilo que se diz "novo" (STRECK, 1995), não só muitas vezes flexibiliza, como também pode vir a sequestrar por completo as garantias fundamentais, sob o mascaramento da retórica socioeducativa. Isso se torna um acinte aos ideais cristalizados num Estado Democrático de Direito, tornando a práxis jurídica algo odioso.

A conclusão que se extrai é que os códigos ideológicos, inseridos no processo de interpretação retrospectiva, atuam desde o deflagramento inicial do procedimento 
investigativo (inquérito policial) até depois da prolação da sentença, e incorporando-se à pessoa desviante, constroem, ainda que de forma inconsciente, o Outro, alvo da tutela estatal.

O processo de etiquetamento, que se inicia no primeiro suspiro de reação social à conduta taxada como desviante, culmina na atuação - não tão magistral - dos magistrados quando, imbuídos socialmente do espírito de justiceiros ou, pior, do espírito paterno (o que nos remete à retrógrada Doutrina da Situação Irregular), em nome do bem do adolescente ou em nome do afastamento do grau de periculosidade (termo onde tudo cabe), usa de informações e dados que declaradamente selecionam uma parcela da população. Seja porque crê na capacidade de regeneração do sistema penal (comprovadamente falida), seja porque acredita de fato nos discursos velados do sistema, sendo nada mais nada menos que uma peça fundamental do jogo punitivo contemporâneo (ROSA, 2004).

Há uma finalidade e funcionalidade do sistema de controle social. Isso é um fato. Para os críticos do labeling approach, o desviante é quase um inimigo social, que pratica atos fora do padrão esperado como forma de luta política. Para FOUCAULT (1987), esse desviante "[...] traz consigo o perigo múltiplo da desordem, do crime, da loucura". Mas o Estado pretende manter o status quo. Assim, reagem os "homens de bem", nascem os desviantes, criam-se os estereótipos, internalizam-se os pré-conceitos e pré-juízos.

Propunham os novos criminólogos do embrionário projeto da futura Criminologia Crítica uma análise mais profunda da função que cumpre o Estado, as leis e as instituições legais na manutenção de um sistema de produção. Feito isso e seguindo as análises dos dados feitos até o momento, pode-se verificar uma efetiva presença de códigos ideológicos retóricos referentes à natureza da medida na maioria das sentenças de internação dos jovens em conflito com a lei, ocultando uma vergastada intenção punitiva.

Constatou-se que o passado do adolescente foi revisitado e valorado de forma não circular, acrítica e sem nenhuma inclinação a realizar os procedimentos de estranhamento (STRECK, 1995), utilizando a vida pregressa não como fator de individualização da pena, com a tendência de ampliação da esfera de liberdade, mas como verdadeiro foco de interpretações retrospectivas fundamentadoras da aplicação da medida.

Rotulou-se pelos meios mais estapafúrdios o jovem como criminoso, ao arrepio de uma salutar hermenêutica. E, para agravar, não obstante a erroneamente se interpretar retrospectivamente, ainda fez-se uso de tal equívoco para fundamentar a medida em superficiais necessidades pedagógicas, que não fazem o papel de motivos, mas de fins.

Dessa forma, observa-se uma confirmação da hipótese inicial de existência de uma criminalização secundária baseada em ideologias, pressão popular e estereotipias, através do mecanismo da interpretação retrospectiva schuriana, perante o uso indiscriminado da ideia de socioeducação/responsabilização.

Infelizmente, por limitações práticas e de acúmulo teórico, a vigente pesquisa ainda não se propõe a mergulhar no ambiente de discussão acerca da real natureza da medida socioeducativa. Mas, após o exposto acima, conseguiu problematizar algumas certezas quanto a esta natureza. Sua definição, inclusive, ainda que numa inovação, ao considerá-la uma medida sui generis porquanto fundada na responsabilização educativa, 
é premente. Caso contrário: O juiz neutro decai. A salvaguarda de direitos fundamentais não se efetua. Os pilares da democracia, de uma forma ou de outra, são colocados em perigo.

\section{Referências bibliográficas}

ANDRADE, V. R. P. de. A ilusão de segurança jurídica: do controle da violência à violência do controle penal. Porto Alegre: Livraria do Advogado, 1997.

ANITUA, G. I. História dos pensamentos criminológicos. Rio de Janeiro: Revan, 2008.

ANIYAR DE CASTRO, L. Criminologia da libertação. Rio de Janeiro: Revan, 2005.

BARATTA, A. Criminologia crítica e crítica do direito penal. 2 ed. Rio de Janeiro: Freitas Bastos, 1999.

BARDIN, L. Análise de conteúdo. Lisboa: Edições 70, 1997.

BECKER, H. Outsiders: estudos de sociologia do desvio. Rio de Janeiro: Zahar, 2008.

CAMPOS, C. J. G. Método de análise de conteúdo: ferramenta para a análise de dados qualitativos no campo da saúde. Revista Brasileira de Enfermagem Brasília, vol.57, n.5, Set./Out, 2004.

CARVALHO, S. Revisita à desconstrução do modelo jurídico inquisitorial. Disponível em< Disponível em: http://www.buscalegis.ufsc.br/revistas/files/anexos/32639-39993-1-PB.pdf Acesso em 10 de junho de 2014.

CARVALHO, S. O papel dos atores do sistema penal na era do punitivismo: o exemplo privilegiado da aplicação da pena. Rio de Janeiro: Lumen Juris, 2010.

CNJ. Programa Justiça ao Jovem. Relatório Pernambuco, 2011. Disponível em <http://www.cnj.jus.br/images/programas/justica-ao-jovem/pernambuco.pdf $>$. Acesso em 05/07/2013

COSTA, A. P. M. As garantias processuais e o Direito Penal Juvenil. Porto Alegre: Livraria do Advogado, 2005.

DEL OLMO, R. América Latina e sua criminologia. Rio de Janeiro: Revan, 2004.

FERRAJOLI, Luigi. Prefácio a Infância, ley y democracia en América Latina. Compiladores: MÉNDEZ, Emilio García; BELOFF, Mary. Buenos Aires: Temis, 1999. FOUCAULT, M. A Verdade e as formas jurídicas. 3 ed. Rio de Janeiro: NAU, 2009. FOUCAULT, M. Vigiar e punir: história da violência nas prisões. 5. ed. Petropólis: Vozes, 1987.

LARRAURI, E. La herencia de la criminología crítica. 3 ed. México: Siglo XXI de España, 2000.

MÉNDEZ, E. G. Adolescentes e responsabilidade penal: um debate latino-americano. Porto Alegre: AJURIS, ESMP-RS, FESDEP-RS, 2000.

MÉNDEZ, E. G. Infância e cidadania na América Latina. São Paulo: Hucitec/Instituto Ayrton Senna, 1998.

MILL, J. S. Apud BOBBIO, Norberto. A Era dos Direitos. Traduzido por Carlos Nelson Coutinho. Rio de Janeiro: Campus, 1992.

MIRANDA COUTINHO, J. N. de; CARVALHO, E. R. Teoria das janelas quebradas: e se a pedra vem de dentro? Disponível em: 
<http://egov.ufsc.br/portal/sites/default/files/anexos/11716-11716-1-PB.htm>. Acesso em: 11 jul. 2014.

OLIVEIRA, L. Não fale do Código de Hamurábi! A pesquisa sócio-jurídica na pósgraduação em Direito. In: Sua Excelência o Comissário e outros ensaios de sociologia jurídica. Rio de Janeiro: Letra Legal Editoria, 2004.

OTERO, J. M. A hipocrisia e a dor no sistema de sanções do direito penal. Discursos Sediciosos: crime, direito e sociedade, Rio de Janeiro, 2007.

PAVARINI, M. Control y dominacíon: teorias criminológicas burguesas y proyecto hegemónico. México: Siglo Veintiuno Editores, 1983.

RAMIDOFF, M. L. Lições de direito da criança e do adolescente: ato infracional e medidas socioeducativas. São Paulo: JURUA, 2011.

ROSA, A. M. da. Decisão no processo penal como bricolage de significantes. 2004. 420 fls. Tese (Doutorado)- Setor de Ciências Jurídicas e Sociais, Universidade Federal do Paraná. Curitiba, 2004.

ROSA, M. A Era do escândalo - Lições, Relatos e Bastidores. São Paulo: Geração Editorial, 2003.

SARAIVA, J. B. C. Adolescente em Conflito com a Lei: da indiferença à proteção integral: uma abordagem sobre a responsabilidade penal juvenil. 3 ed. Porto Alegre: Livraria do Advogado, 2009.

SCHUR, E. M. Labeling deviant behavior - its sociological implications. Nova Iorque: Harper and Row, 1971.

STRECK, L. L. Súmulas no direito brasileiro: eficácia, poder e função. Porto Alegre: Livraria do Advogado, 1995, p. 249

ZAFFARONI, E. R. O inimigo no direito penal. 2.ed. Trad. Sérgio Lamarão. Rio de Janeiro: Revan, 2007.

ZAFFARONI, E. R. Criminología: aproximación desde un margen. Bogotá: Editorial Temis, 2003.

ZAFFARONI, E. R.; BATISTA, N., et al. Direito Penal Brasileiro I: Teoria Geral do Direito Penal. Rio de Janeiro: Revan, 2003.

ZAFFARONI, E. R. PIERANGELI, J. H. Manual de Direito Penal Brasileiro. São Paulo: Revista dos Tribunais, 2002. 